\section{FRASES IMPUNTUALES}

\author{
Diana Marlene
}

*

Un viejo bolero crea desobediencia de lágrimas a las que un varón disciplinó para que no salieran.

*

A veces, tal como en tiempos de vendimia e idilio, las musas solo ansían algún atisbo mientras uno va mirando por la ventana del autobús.

Dejé de huir, porque siempre me anticipé atrapada.

Diana Marlene, nacida en Xalapa, Ver., y actual estudiante de la licenciatura en Lengua y Literatura Hispánicas en la UV, es escritora y cantante versátil.

vistas o crónicas de varias noches difíciles e intensas. Entre otros desfilan Big Joe Williams, Sylvia Embry, Phil Meeks, Larry Davis, Magic Slim, Brownie McGhee, Blind John Davis, Papa John Creach, Frank Zappa, Muddy Waters, Taj Mahal, Bessie Smith, John Lee Hooker, el mexicanísimo Real de Catorce y la inolvidable Betsy Pecanins.

Es el momento del jazz y Derbez se regodea en este género que encuentra su acta de nacimiento en Nueva Orleans y su paternidad y maternidad, sí, también, en los sensibles, rebeldes e intensos negros.

Con un reconocimiento a Eubie Blake, en pleno goce del ragtime, el autor abre la puerta de ingreso al jazz ("el gran arte de escuchar para escucharte") y de ahí aparece una pléyade inabarcable de luminarias del jazz como Miles Davis, Charlie Haden, Carla Bley,
Archie Shepp, Albert Ayler, Charlie Parker, Charles Mingus, Chucho Valdés, en fin, en las páginas uno se encuentra con los nombres de leyendas que han hecho del jazz una mítica historia entre anécdotas y vivencias que apunta el saxoservidor Alain e incluye hasta un encuentro inesperado con Michelle Pfeiffer.

Jazzamoart, el jazzista de la pintura, ilustra la portada del libro. Y ahí, en la anarquía del movimiento, en el verso libre, en el trazo que da movimiento y cuerpo a la música, podemos visitar y revisitar Pluma en mano. Entre blues y jazz, porque al fin y al cabo, como dice el autor: "eso que suena, ese que suena, soy yo... LPyH

Germán Martínez Aceves es coordinador de la Feria Internacional del Libro Universitario de la UV.

\section{Palabraras}

\section{y acordes}

\section{Relato}

\section{Alfonso Colorado}

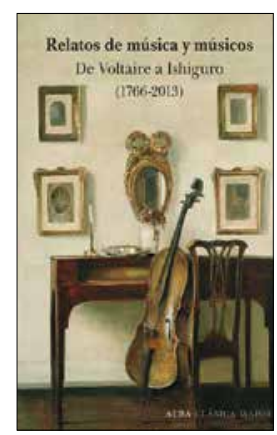

v. v. A. A., Relatos de música y músicos. De Voltaire a Ishiguro (1766-2013), sel. y present. de Marta Salís, v.v. traductores, Barcelona, Alba, 2018, 730 pp.

os 44 textos de esta recopilación, seleccionados y presentados por la traductora española Marta Salís, muestran que el ámbito de la música no es solo el de las emociones o el entretenimiento; su dominio es tan amplio como la experiencia humana. Si aquí aparecen sonatas y sinfonías, también tienen un lugar soeces canciones verdes y agresivas canciones de guerra (Daudet); en pocos minutos una canción de metalcore, llena de insultos y malas palabras, evidencia la inmensa grieta generacional entre una madre y su hija (Roche). La música sirve también como salvoconducto para abordar temas delicados o hasta prohibidos, como en una canción melosa que se refiere a la prostitución (Rhys) o como arena de debate, por ejemplo, entre la manera de entender la música y la vida de una pianista afroamericana y su mecenas anglosajona (Hughes). La música es 